\title{
Oromandibular and Laryngeal Dystonia Secondary to Dystonia 6 Due to THAP1 Variant in a Child
}

\author{
Vykuntaraju K. Gowda ${ }^{1}$ (1) - Manojna Battina ${ }^{1} \cdot$ Varunvenkat M. Srinivasan $^{1} \cdot$ Sanjay K. Shivappa ${ }^{2}$
}

Received: 16 February 2021 / Accepted: 26 March 2021 / Published online: 9 April 2021

(C) Dr. K C Chaudhuri Foundation 2021

To the Editor: Oromandibular dystonia (OMD) is a form of focal dystonia involving laryngeal or craniocervical muscles [1]. DYT6 dystonia is a common cause of generalized dystonia but commonly starts with OMD [1]. We are reporting a rare case of early-onset OMD secondary to dystonia 6.

A 5-y-old female child presented with dysarthria and abnormal twisting of the right-sided upper limb and fingers. On examination, dysarthria, dystonia in the right side of the face, tongue, and right hand was noted. On investigation, complete hemogram, liver function tests, renal function tests, serum ammonia, serum lactate, tandem mass spectrometry, serum copper, serum ceruloplasmin, $24 \mathrm{~h}$ urine copper, and MRI of the brain were normal. The cerebrospinal fluid analysis was normal and negative for autoantibodies. The next-generation sequencing showed a heterozygous variant c.427 $\mathrm{A}>\mathrm{G}$ (p. Met143Val) in exon 3 of THAP1 gene. The child was treated with levodopa-carbidopa, tetrabenazine, and trihexyphenidyl which showed mild improvement in dystonia but no improvement in speech.

Dystonia 6 is an autosomal dominant dystonia due to mutations in THAP1 and presents with an average age of onset $18 \mathrm{y}$ with focal to generalized dystonia and incomplete penetrance [2]. Our child presented at $5 \mathrm{y}$ of age, so early onset has not been reported. This case started with focal dystonia of onesided laryngeal, facial, and upper-limb dystonia. The Wilson disease (WD), autoimmune encephalitis, post-infective dystonia, and primary dystonia syndromes were considered and ruled out as there was no evidence of the same on investigations. Primary dystonia particularly type 6 was considered particularly due to laryngeal involvement. Houlden et al. [3] and Djarmati et al. [4] reported 9 and 2 variants in THAP1 gene with OMD, respectively. To conclude, dystonia 6 should be considered in the case of craniofacial and laryngeal focal onset primary dystonia in the pediatric age group also.

\section{Declarations}

Conflict of Interest None.

\section{References}

1. Batla A. Dystonia: a review. Neurol India. 2018;66(Suppl S1):4858.

2. Fuchs T, Gavarini S, Saunders-Pullman R, et al. Mutations in the THAP1 gene are responsible for DYT6 primary torsion dystonia. Nat Genet. 2009;41(3):286-8.

3. Houlden H, Schneider SA, Paudel R, et al. THAP1 mutations (DYT6) are an additional cause of early-onset dystonia. Neurology. 2010;74(10):846-50.

4. Djarmati A, Schneider SA, Lohmann K, Winkler S. Mutations in THAP1 (DYT6) and generalized dystonia with prominent spasmodic dysphonia: a genetic screening study. Lancet Neurol. 2009;8(5): 447-52.

Publisher's Note Springer Nature remains neutral with regard to jurisdictional claims in published maps and institutional affiliations.

Vykuntaraju K. Gowda

drknvraju08@gmail.com

1 Department of Pediatric Neurology, Indira Gandhi Institute of Child Health, Bangalore, Karnataka 560029, India

2 Department of Pediatric Medicine, Indira Gandhi Institute of Child Health, Bangalore, Karnataka, India 